\title{
Analysis of the cultural factors affecting the proper design of website and electronic courseware for e-Learning in ASEAN
}

\author{
Jintavee Khlaisang \\ Chulalongkorn University, Thailand
}

\begin{abstract}
This study is to understand perspectives of administrators and instructors in higher educational institutes on cultural factors which affect website and electronic courseware for e-Learning in ASEAN. It used an Exploratory Factor Analysis (EFA) to find underlying cultural factors affecting the design of website and electronic courseware for e-Learning in ASEAN. Based on the factors identified, the proposed model of website and electronic courseware for e-Learning in ASEAN along with the prototype were presented at the end. The research procedures included two major steps. Step 1 is based on the review of related literature and the data collection from the survey concerning cultural factors affecting website and electronic courseware. In step 2, experts' interviews were conducted to obtain their opinions concerning the proposed factors, along with discussion about readiness of Thai e-Leaning in higher education so as to become part of the ASEAN Community in 2015, and the model of website and electronic courseware for e-Learning in ASEAN were presented.

The results of this study were the report of the cultural factors affecting the proper design of website and electronic courseware for e-Learning in ASEAN, the proposed model, and the prototype of website and electronic courseware for e-Learning in ASEAN assimilating all the related cultural factors exquisitely.
\end{abstract}

\section{Introduction}

\section{Background and the purpose of the research}

Thailand Cyber University (TCU), the Office of Higher Education Commission, has initiated e-Learning Professional Program with the purpose of developing educational persons in distance learning since 2005. TCU, cooperating with faculty members from both domestic and international universities, has delivered the program online via Learning Management System (LMS) since 2007. Students enrolling in the program included lecturers and master degree and doctoral degree students majored in Education. E-Learning Professional Program is divided into three tracks: Certificate in e-Learning Teacher, Certificate in e-Learning Courseware Developer, and Certificate in e-Learning Project Management. The program has been successfully implemented with 444 students. 
In order to prepare Thailand's higher education e-Learning for ASEAN Economic Community (AEC), to be a part of ASEAN Socio-Cultural Community (ASCC) in 2015, and to be in accordance with 2012 OHEC strategy in developing and enhancing knowledge and providing education with modern technology to reach international standard, TCU saw the necessity to conduct research on Analysis of the Cultural Factors Affecting the Proper Design of Website and Electronic Courseware for e-Learning in ASEAN. The result of the research will be used to develop the current knowledge and applied to e-Learning Professional Program. Also, it will be a guideline in e-Learning in ASEAN context for educational institutes and lecturers.

Thus the purpose of the research is to analyse cultural factors of the proper design of website and electronic courseware for e-Learning in ASEAN. From the research result, the proper design of website and electronic courseware for higher e-Learning in ASEAN will be proposed and the result will be implemented in the current activities.

\section{Research methodology}

The research procedures included two major steps. Step 1 is based on the review of related literature and the data collection from the survey concerning cultural factors affecting website and electronic courseware. Exploratory Factor Analysis (EFA) was used to explore the possible underlying factors. In step 2, experts' interviews were conducted in order to gain their opinions concerning the proposed factors, along with discussion about readiness of Thai e-Leaning in higher education so as to become part of the ASEAN Community in 2015, and the model and the prototype were presented. The research methodology comprised three phases.

\section{Phase 1}

Study, analyse and synthesise basic information, using an Exploratory Factor Analysis method, on cultural factors of the proper design of website and electronic courseware for e-Learning in ASEAN, emphasising higher educational institutes. It was done by analysing and synthesising at least 50 documents and researches on cultural factors of the proper design of website and electronic courseware for e-Learning in ASEAN during the last 10 years. Literature review was analysed and variables were screened. The information then was generated into a survey.

\section{Phase 2}

Study of expert opinions on culture factors of the website and electronic courseware that are proper for e-Learning in ASEAN to exchange knowledge and experience and prepare Thailand's higher education e-Learning to enter AEC with instructors in e-Learning Professional Program. The data was collected from the survey. The respondents had at least one year's experience in e-Learning. Samples were taken from about 100 participants who attended the International e-Learning Conference: Smart Innovations in Education \& Life Long Learning on 14 and 15 June 2012 organised by TCU. The data obtained from the survey was analysed using the Factor Analysis method. 


\section{Phase 3}

Develop the prototype of website and electronic courseware for e-Learning. The quality of the prototype was tested by experts with minimum three years' experience in e-Learning and representatives from ASEAN. Lastly, the proper design of website and electronic courseware for e-Learning were presented by creating models of website and electronic courseware that are proper for e-Learning in higher education in ASEAN. The model was approved by five experts.

\section{Results analysis}

The result analysis is reported in three parts according to the research methodology as follows:

\section{Phase 1}

The researcher reviewed documents and research on culture relating to the design of website and electronic courseware that is related to cultural factors of ASEAN from 1991-2011, with emphasis on higher educational institutes to be a framework for analysing and synthesising cultural aspects. This information was also used to develop a prototype of the proper design of website and electronic courseware for e-Learning in ASEAN that could respond to cultural differences. There were 25 documents and research on the design of website in ASEAN. They comprised seven documents and research from Thailand, four from the Philippines, four from Japan, four from Malaysia, three from Singapore, two from South Korea and one from China. (Japan, China, and South Korea were included according to ASEAN+3 collaboration). There were 25 documents and research on the design of electronic courseware in ASEAN. They comprised 10 documents and research from Thailand, two from the Philippines, six from Malaysia, two from Singapore, one from Vietnam and four from China. Accordingly, cultural factors can be divided into 10 factors: (1) Sex, (2) Religion, (3) Language, (4) History, (5) Art, (6) Aesthetics, (7) Law, (8) Politics, (9) Ethnicity and (10) Local wisdoms. The 10 cultural factors are directly related to the design, while there were also indirect factors that are related to the design of website and electronic courseware. They are (1) Multimedia design, (2) Screen design, (3) Content design and (4) Characteristics of new media.

\section{Phase 2}

The data obtained from the survey was analysed using the Factor Analysis method with the following steps. (1) Selecting factors. Because this study used a sample of 140 people, factor loading was set at .50 (Hair, 1995). (2) Selecting factors with variable (at least three questions). Since Factor 7 had only two variables (questions) that have factor loading above .50, it was not considered (as well as the later factors). (3) Factor analysis steps include (3.1) reporting the descriptive statistics of questions, (3.2) testing $\mathrm{KMO}$ value, (3.3) analysing Eigen/factor value, (3.4) extracting the factors, and (3.5) naming the factors as presented in the later section. 
Analysis of the cultural factors affecting the proper design of website and

electronic courseware for e-Learning in ASEAN

Part 1 General information of the sample

About 40 per cent of the samples worked in universities, and most of them were in the Faculty of Education/Industrial Education (27.86 per cent). The respondents included Vice Dean/ Deputy Director (7.86 per cent). Most age group was between 31-40 years (36.43 per cent) and most of them were Buddhists (93.57 per cent). The majority of the respondents graduated with a Master's Degree (57.86 per cent) and lecturers (50.71 per cent). As for working experience, most respondents had working experience less than 5 years (36.43 per cent).

Part 2 Analysis of the factors on website

Basic statistics on website: it was found that the score of 86 factors on website out of the total factors had average score of between 3.26 to 4.68 and a standard deviation between 0.51 and 1.17. Analysis of the factors on the website: the researcher used the survey to analyse factors on the website by extracting factors using Principal Component Analysis method and analysing Orthogonal Rotation by Varimax Method. The results are shown below.

\section{Extracting factors}

Extracting factors using Principal Component Analysis method obtained factors, Eigen value, Percentage of Variance, Cumulative Percentage of Variance, and Factor Loading of the survey on the website. The results of the two preliminary methods confirmed that data collected from the sample was appropriate to analyse the factors on the website.

The analysis of the communality found that the initial communality value obtained from Principal Component Analysis (PCA) method of all questions was equal to1.000 and after the extraction of the factors, was higher than 0.2 . This indicated that questions were appropriate for further factor analysis.

There were 18 factors which had Eigen value higher than 1.00 which was the sum of the squares of the coefficients of each factor. Considering the 18 factors, it was found that Cumulative Percentage of Variance of the 18 factors was 75.153 of the total variance. 


\section{Axis rotation}

The researcher analysed Orthogonal Rotation using the Varimax Method to make the variables associate with the factors more clearly. The details are as follows.

Out of loading factor value of 88 factors, there were 18 factors that had loading factor value higher than .50 . Factors that were considered to be clear according to the criteria had to have at least three variables in one factor. There were 18 factors that had loading factor value higher than .50 after Orthogonal Rotation using Varimax Method. The example is as follows:

Factor 1: 23 variables, items 3.18, 3.19, 3.13, 3.14, 3.8, 3.12, 3.6, 3.20, 3.22, 3.23, $3.16,3.10,3.17,3.29,1.32,3.15,3.21,3.2,3.9,1.33,3.7,3.27$ and 3.5

Factor 2: 9 variables, items 3.42, 3.38, 3.39, 3.41, 3.40, 3.34, 3.35, 3.36, and 3.37

Factor 3: 8 variables, items $1.41,1.44,1.40,1.43,1.45,1.46,1.39$ and 1.42

Factor 17: 1 variable, item 1.34

Factor 18: 0 variable

Considering 86 variables in the survey on website, there were eight factors that had loading value higher than .50 but had variables less than 3 variables, including factors $7,12,13,14,15,16,17$ and 18 . These were less than the criteria which was set to have no less than 3 variables in the factor. Therefore, they were removed. Then, there were 10 clear factors: $1,2,3,4,5,6,8,9,10$ and 11 , a total of 63 variables. The researcher analysed factors using Scree test as shown in Picture 1. 


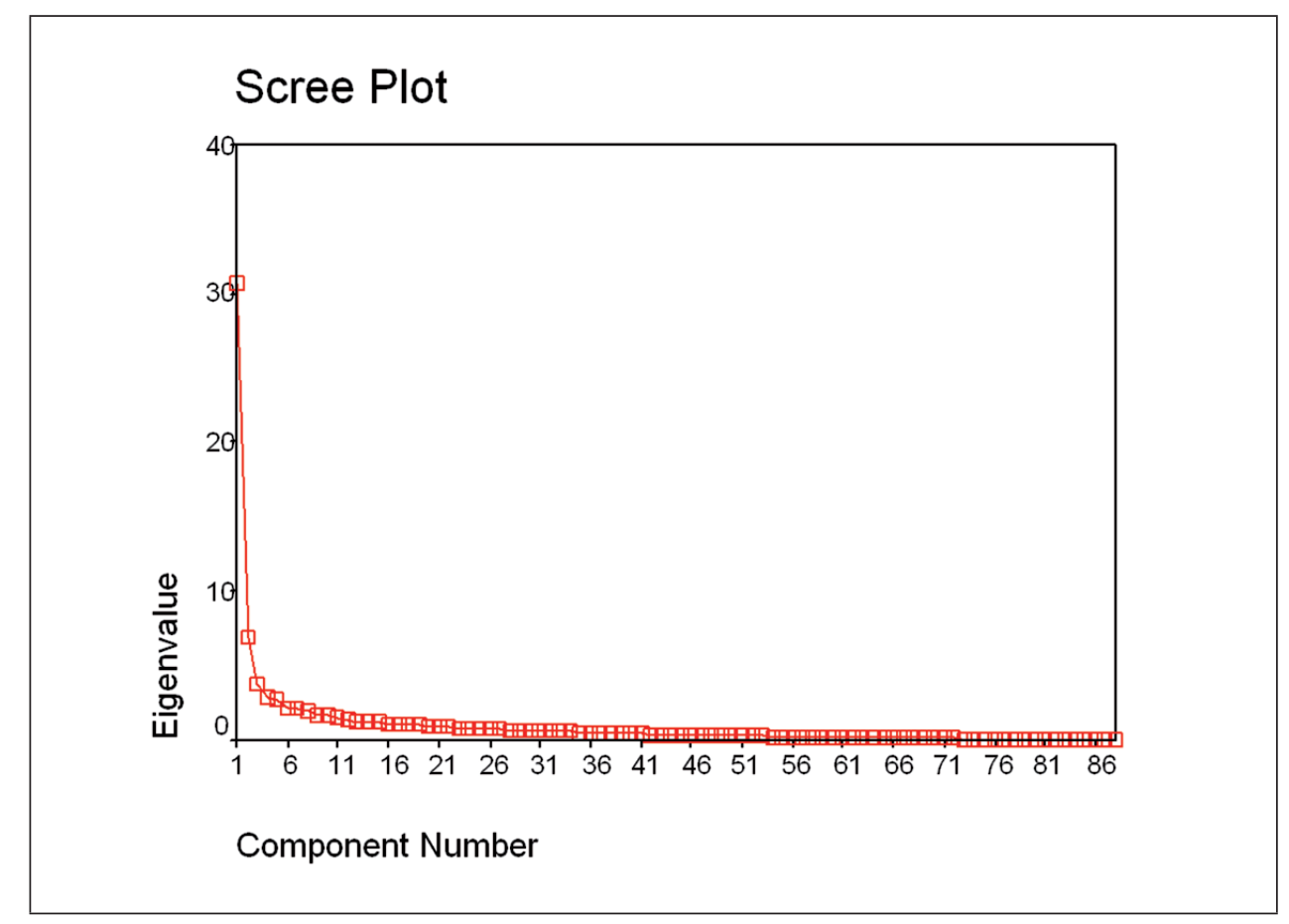

Picture 1 Eigen of the Factors on Website Design

The result as shown in Picture 1 found that when using Scree-test on Eigen value of the factors on website, there were 10 clear factors: $1,2,3,4,5,6,8,9,10$ and 11.This was consistent with the analysis of loading factor after Orthogonal Rotation using Varimax Method.

3. Naming the factors

The researcher named 10 factors according to the analysis by considering the factor loading and overall statements included in the factor. The example of factor 3 is as follows.

\begin{tabular}{|c|l|c|}
\hline Variable (Item) & \multicolumn{1}{|c|}{ Message } & Factor loading \\
\hline 1.41 & $\begin{array}{l}\text { Present the lifestyle of living of each } \\
\text { country. }\end{array}$ & .708 \\
\hline 1.44 & $\begin{array}{l}\text { Includes information on the local } \\
\text { knowledge management of countries in } \\
\text { ASEAN. }\end{array}$ & .686 \\
\hline 1.40 & $\begin{array}{l}\text { Present the history of the precious } \\
\text { heritage, historic sites, and artifacts. }\end{array}$ & .633 \\
\hline
\end{tabular}




\begin{tabular}{|c|l|c|}
\hline 1.43 & $\begin{array}{l}\text { Present local wisdoms of countries in } \\
\text { ASEAN. }\end{array}$ & .630 \\
\hline 1.45 & $\begin{array}{l}\text { Connect similar or related information of } \\
\text { each country. }\end{array}$ & .626 \\
\hline 1.46 & $\begin{array}{l}\text { Present how to apply local knowledge into } \\
\text { practice for sustainable development. }\end{array}$ & .592 \\
\hline 1.39 & Present the history of the race. & .543 \\
\hline 1.42 & Present native fiction and folklore. & .512 \\
\hline
\end{tabular}

Table 1 Factor 3

Table 1 shows that there are eight variables in Factor 3 with factor loading between .512 and .708 and Eigen value at 3.710. It included four variables on ethnicity $(1.39,1.40$, $1.41,1.42)$, and four variables on local wisdoms $(1.43,1.44,1.45,1.46)$. Considering frequency, it was found that variables on ethnicity and variables on local wisdoms had the same frequency. Therefore, this factor was named "Ethnicity and local wisdoms".

Part 3 Analysis of the factors on electronic courseware

Basic statistics on electronic courseware: it was found that the score of 88 factors on electronic courseware had an average score of between 3.19 to 4.63 and a standard deviation between 0.54 to 1.19 .

Analysis of the factors on electronic courseware: the researcher used the survey to analyse factors on electronic courseware by extracting factors using Principal Component Analysis method and analysing Orthogonal Rotation by Varimax Method. The results are shown below.

1. Extracting factors

Extracting factors using Principal Component Analysis method obtained factors, Eigen value, Percentage of Variance, Cumulative Percentage of Variance, and Factor Loading of the survey on the electronic courseware. The results of the two preliminary methods confirmed that data collected from the sample was appropriate to analyse the factors on electronic courseware.

The analysis of the communality found that the initial communality value obtained from Principal Component Analysis (PCA) method of all questions was equal to 1.000 and after the extraction of the factors was higher than 0.2 . This indicated that questions were appropriate for further factor analysis. 
There were 16 factors which had Eigen value higher than 1.00 which was the sum of the squares of the coefficients of each factor. Considering the 16 factors, it was found that Cumulative Percentage of Variance of the 16 factors was 75.155 of the total variance.

\section{Axis rotation}

The researcher analysed Orthogonal Rotation using Varimax Method to make the variables associate with the factors more clearly. The details are as follows.

Out of loading factor value of 88 factors, there were 16 factors that had loading factor value higher than .50 . Factors that were considered to be clear according to the criteria had to have at least 3 variables in 1 factor. The details are as follows.

There were 16 factors that had loading factor value higher than .50 after Orthogonal Rotation using Varimax Method. The example is as follows:

Factor 1: 25 variables, items 4.20, 4.32, 4.18, 4.37, 4.22, 4.39, 4.30, 4.25, 4.21, $4.33,4.35,4.41,4.36,4.17,4.34,4.26,4.29,4.19,4.31,4.24,4.23,4.40$, $4.38,4.28$, and 4.27

Factor 2: 13 variables, items $2.25,2.20,2.18,2.19,2.27,2.17,2.26,2.43,2.44$, $2.41,2.40,2.28$ and 2.42

Factor 3: 6 variables, items 2.33, 2.31, 2.32, 2.34, 2.24, and 2.30

Factor $16: 1$ variable, item 4.6

Considering 88 variables in the survey on electronic courseware, there were seven factors that had loading value higher than .50 but had variables less than three variables, including factors $7,11,12,13,14,15$ and 16 . These were less than the criteria which was set to have no less than three variables in the factor. Therefore, they were removed. Then, there were nine clear factors: 1, 2, 3, 4, 5, 6, 8, 9 and 10, a total of 68 variables.

The result found that when using Scree-test on Eigen value of the factors on website, there were nine clear factors: 1, 2, 3, 4, 5, 6, 8, 9 and 10. This was consistent with the analysis of loading factor after Orthogonal Rotation using Varimax Method. 


\title{
3. Naming the factors
}

\begin{abstract}
The researcher named nine factors according to the analysis by considering the factor loading and overall statements that are included in the factor. The example of factor 2 was named "History and ethnicity" since the analysis shows that there are 13 variables in Factor 2 with factor loading between .563 and .786 and Eigen value at 8.111. It included four variables on history $(2.17,2.18,2.19,2.20)$, two variables on art $(2.25$, $2.26)$, two variables on aesthetics $(2.27,2.28)$, four variables on ethnicity $(2.40,2.41$, $2.42,2.43)$, and one variable on local wisdom (2.44). Considering frequency, it was found that variables on history and ethnicity had the highest frequency and most factor loading.
\end{abstract}

\section{Phase 3}

Based on the result from phase 2, the prototype of website and electronic courseware for e-Learning in ASEAN were developed. The qualities of the models were examined by experts who have experiences in e-Learning for at least three years and/or representatives from ASEAN. Lastly, the proper design model of website and electronic courseware were presented and were approved by five experts. The factors and the models were presented as follows.

The proper design model of website should include the following nine cultural factors which comprised of six direct factors and three indirect factors which totalled 56 variables. The six direct factors are: (1) Ethnicity and local wisdoms (8 variables): (1.1) Present the lifestyle of living of each country, (1.2) Includes information on the local knowledge management of countries in ASEAN, (1.3) Present local wisdoms of countries in ASEAN, (1.4) Connect similar or related information of each country, (1.5) Present the history of the precious heritage, historic sites, and artifacts, (1.6) Present how to apply local knowledge into practice for sustainable development, (1.7) Present native fiction and folklore, (1.8) Present the history of the race. (2) Aesthetics and Art (3 variables): (2.1) Present the uniqueness of each country's local culture, (2.2) Combine a variety of media to present each country's culture, and (2.3) Present traditional art but modify the presentation to be more interesting. (3) Language (1 variable): (3.1) Use official language of each country. (4) Religion (4 variables): (4.1) Use combined emotional icons that are appropriate for both male and female, (4.2) Use religious icons on the first page of ASEAN website, (4.3) Publicise activities and religious news but not include product advertising, (4.4) Have contents about religious beliefs that religious person can study. (5) Politics (2 variables): (5.1) Connect to political news of countries in ASEAN, and (5.2) Include political news of countries in ASEAN. (6) Law (3 variables): (6.1) Consider the copyright when copying or reproducing contents, (6.2) Check the reference to prevent intellectual properties issue, and (6.3) Consider copyright and reference when designing contents. The three indirect factors are: (1) Screen and multimedia design (23 variables): (1.1) Have a channel for communication between users and system administrators, (1.2) Enable users to access information on every page easily, (1.3) Use standard navigation buttons to make it easy to understand, (1.4) Use a link that is easy to access and not complicated, (1.5) Have 
links to the content information inside and outside the website, (1.6) Use text that is clear and easy to read with different sizes to show priorities of the contents, (1.7) Have a variety of communication channels, (1.8) Have clear, accurate, concise, and updated contents and user-friendly language, (1.9) Organise the components in the page to be consistent, (1.10) Enable users to return to the previous page and navigate to the desired page without confusion and have continuous interactions, (1.11) Refer to the source, (1.12) Select contents from a reliable source, (1.13) Screen should be designed to be striking and eye-catching, (1.14) Have a guideline to help users finish their learning by themselves, (1.15) Use menus which are easy to understand and convey meaning, (1.16) Design e-Learning website to be simple and universal, (1.17) Have an evaluation of the presentation, learning activities, and online tools that are related, (1.18) Present contents based on an original story but modify the presentation to be interesting, (1.19) Use layout, size, and position that is consistent throughout the website, (1.20) Design e-Learning website to show the uniqueness and history of ASEAN, (1.21) Use internal layout that is easy to access main data and secondary data, (1.22) Use images that do not conflict with culture, and (1.23) Use dark colour text on light background and light colour text on dark background. (2) Content design (3 variables): (2.1) Have interactive contents constantly, (2) Have a post-test to check learners' understanding, and (3) Have contents that reflect local identity of different countries in ASEAN. (3) New media (9 variables): (3.1) Divide contents into sub-topics to enable more flexible learning, (3.2) Mobile Learning enables real-time chat from any location at any time, (3.3) Designing for handheld devices enable text to be read both vertically and horizontally. The text does not exceed the screen when reading vertically, (3.4) Use the scrollbar only where necessary to avoid users' inconvenience, (3.5) Contents in e-book format are available, (3.6) Reduce the size of content file for fast download and smaller usage of memory, (3.7) The screen of handheld devices is bright and has high resolution, (3.8) Text and colour of text can be read clearly in handheld devices, and (3.9) Use short video clips, not more than 5-10 minutes.

The proper design model of electronic courseware should include the following eight cultural factors which comprised of five direct factors and three indirect factors which totalled 63 variables. The five direct factors are: (1) History and Ethnicity (13 variables): (1.1) Emphasise on the cultural uniqueness and reflection of each country, (1.2) Consider relation between different cultural contents in each country, (1.3) Have the design that enables learners to access the diversity of culture of each country, (1.4) Present original story but modify the presentation to be more interesting, (1.5) Present native fiction and folklore, (1.6) Present contents related to local information of countries in ASEAN, (1.7) Present traditional art but modify the presentation to be more interesting, (1.8) Combine local historical contents of each country, (1.9) Present the uniqueness of each country's local culture, (1.10) Present the history of the precious heritage, historic sites, and artifacts, (1.11) Combine a variety of media to present each country's culture, (1.12) Present the lifestyle of living of each country, (1.13) 
Present the history of the race. (2) Language (3 variables): (2.1) Have official language subtitle, (2.2) Have English subtitle, and (2.3) Have dialect subtitle. (3) Wisdoms (3 variables): (3.1) Design course content to be according to education level in different countries in ASEAN, (3.2) Includes information on the local knowledge management of countries in ASEAN, (3.3) Link similar or related information of each country. (4) Religion (2 variables): (4.1) Present taboo and religious beliefs of countries in ASEAN, and (4.2) Present religious regulations in daily life of countries in ASEAN. (5) Law (6 variables): (5.1) Refer to the source, (5.2) Consider the copyright when copying or reproducing contents, (5.3) Select contents from a reliable source, (5.4) Contents are easy to understand, using a variety of media, (5.5) Present contents in sequence and emphasise on basic information which lead to primary knowledge, understanding, and skills, (5.6) Check the reference to prevent intellectual properties issue. The three indirect factors are: (1) Screen design (6 variables): (1.1) Use link icons and graphic or text that have the same standard and convey meaning, (1.2) Use menus that are easy to understand, (1.3) Have a navigation system that is convenient and easy to use, (1.4) Use the link which is fast, simple and flexible to access a variety of contents, (1.5) Put the menu in the same position of every screen, (1.6) Use text and text colour that is clear and easy to read. (2) Content design (25 variables): (2.1) Divide contents into sub-topics to enable more flexible learning, (2.2) Use the lessons that can interact with learners any time, (2.3) Evaluate the continuity of contents, (2.4) Present contents in the same pattern as learning with the instructor directly, (2.5) Allow learners to review the lesson any time they like, (2.6) Designing for handheld devices that enable text to be read both vertically and horizontally. The text does not exceed the screen when reading vertically, (2.7) Text and colour of text can be read clearly in handheld devices, (2.8) Allow learners to participate in activities and learning contents regularly, (2.9) Contents are organised from easy to difficult and are suitable for learners, (2.10) Divide contents to be short modules or group into categories, (2.11) Use updated contents, (2.12) Allow learners to know their progress regularly, (2.13) Course content is designed according to education level in different countries in ASEAN, (2.14) Language level in the lesson is suitable for the level of students, (2.15) Evaluate the correctness of language, (2.16) Provide suggestions/help for using courseware, (2.17) Use learning guidelines, (2.18) Use short video clips, not more than 5-10 minutes, (2.19) Contents in e-book format are available, (2.20) Provide contents that associate with the local issues of countries in ASEAN, (2.21) The screen of handheld devices is bright and has high resolution, (2.22) Display content topic and locate the current location, (2.23) Present contents that are related to culture of countries in ASEAN, (2.24) Design contents that include text, images, graphics, animation, video and sound, (2.25) Provide exercises in each lesson and display the results, and (3) Multimedia (5 variables): (5.1) Use images that convey the meaning according to learning purposes and contents, (5.2) Use video clips that relate to local culture, (5.3) Use video clips as supplement of contents, (5.4) Use a variety of media or combined media, (5.5) Use animation. 
Analysis of the cultural factors affecting the proper design of website and electronic courseware for e-Learning in ASEAN

Based upon the results from the questionnaires, the Exploratory Factor Analysis (EFA), the interviews and the confirmation from ASEAN experts, the proper design models of website design and electronic courseware for e-Learning in ASEAN were proposed as follows:

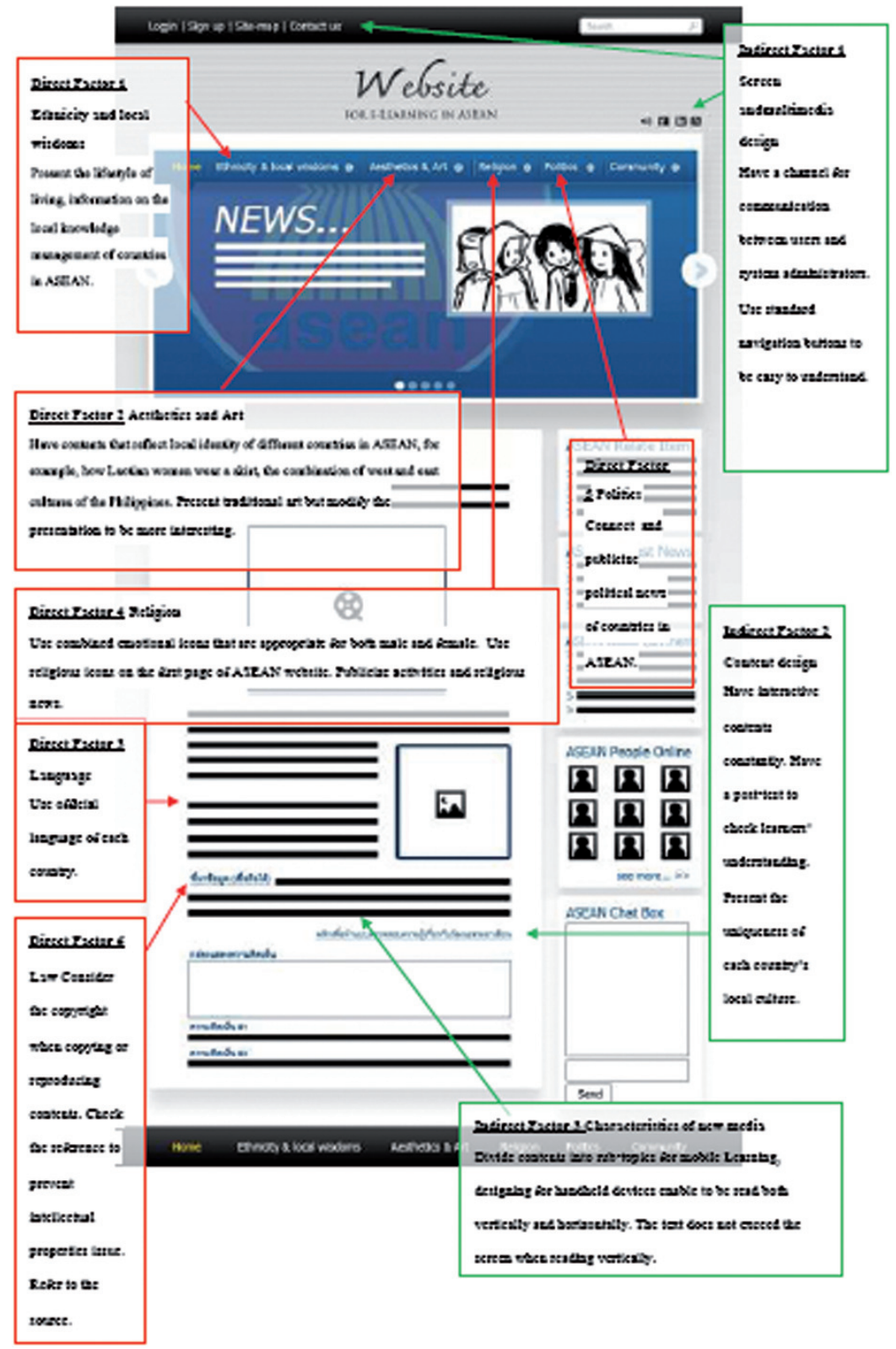

Picture 2 Proper Design Model of Website for e-Learning in ASEAN 


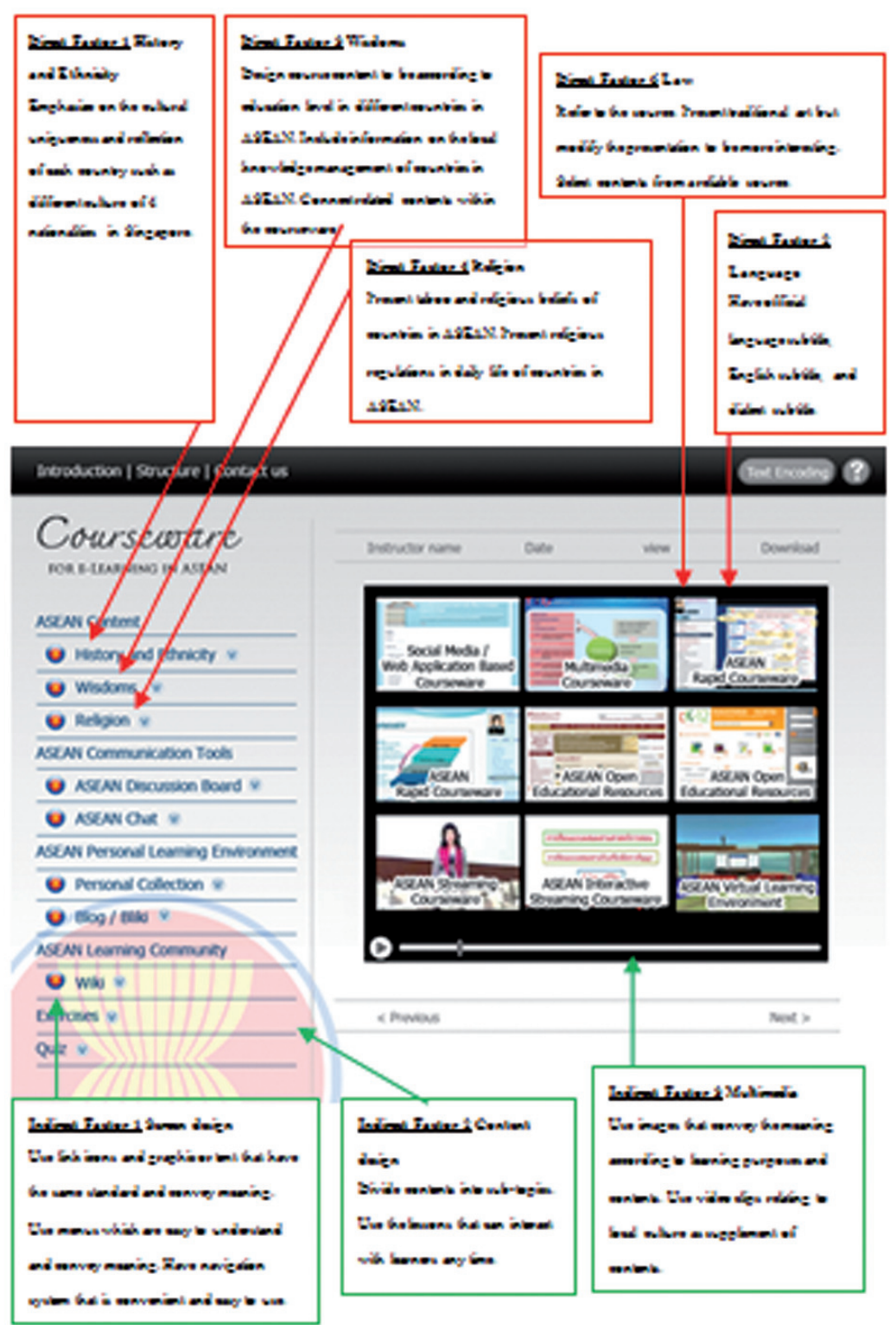

Picture 3 Proper Design Model of Courseware for e-Learning in ASEAN 
Analysis of the cultural factors affecting the proper design of website and

electronic courseware for e-Learning in ASEAN

\section{Conclusion}

This research shows cultural factors that affect the design of website and electronic courseware in ASEAN both directly and indirectly through three phases of research methodology. ASEAN countries will benefit from the design and developed models. Also, it can help prepare Thailand to enter ASEAN Economic Community (AEC) and ASEAN Socio-Cultural Community (ASCC) in 2015 and respond to 2012 OHEC strategy in developing and enhancing knowledge and providing education with modern technology to reach international standard. However, when designing and implementing website and electronic courseware, what should be taken in consideration are the freedom of users to choose contents that reflect culture with the properness in content, context, lesson and learning management. The ASEAN community with the complement of social media and Web 3.0 technologies, i.e., ASEAN wiki, ASEAN virtual lab, and ASEAN virtual learning environment, should be taken in consideration as well as motivation, collaboration in this learning society through activity-based learning with meaningful cultural contents reflecting ASEAN identity. Also, various types of e-Learning tools towards policy making, the frameworks, as well as the contents, i.e., ASEAN OCW, ASEAN OER, should be provided in order to prepare readiness for all ASEAN member countries, and in responding to the ASEAN motto "One Vision, One Identity, One Community".

Jintavee Khlaisang (email: jintavee.m@chula.ac.th) is with the Department of Educational Technology and Communications, Chulalongkorn University, Bangkok, Thailand.

\section{References}

Supatra Suphap. (2000). Thai Society and Culture, Values, Family, Religion, Tradition (1 $1^{\text {th }}$ edition). Bangkok: Thaiwattana Panish.

ASEAN Secretariat. (2009). Culture and Information. [online]. Retrieved from http://www. aseansec.org/ 10373.htm

ASEAN University Network. (2012). ASEAN University Network. Retrieved from http:// www.aun-sec.org

Kakabadse, N.K., \& Kouzmin, A. (1999). Designing for cultural diversity in an IT and globalizing milieu: Some real leadership dilemmas for the new millennium. Journal of Management Development, 18(3), 291-319.

Khlaisang, J. (2012). Analysis of the Cultural Factors Affecting the Proper Design of Website and Electronic Courseware for e-Learning in ASEAN (Research report). Thailand Cyber University (TCU), the Office of Higher Education Commission, Thailand. 
Khlaisang, J. (2012, August). Proper Design of Website and Electronic Courseware for e-Learning in ASEAN: Cultural framework for Consideration. Proceedings of the National e-Learning Conference (NEC 2012): Integrating ASEAN Online Learning: Policy and Process. Thailand Cyber University, Office of Higher Education Commission.

Khlaisang, J. (2011, August). E-Learning Website and Courseware: Current State and Future Trends. Proceedings of the National e-Learning Conference: Open Learning - Open the World (NEC 2011). Thailand Cyber University, Office of Higher Education Commission.

McLoughlin, C. (1999). Culturally responsive technology use: developing an on-line community of learners. British Journal of Educational Technology, 30(3), 231 -243.

Nguyen, L.V. (2008). The Triangular Issues in Multimedia Language Courseware Design in the Vietnamese EFL Environment. Asian Social Science, 4(6), 65-68.

Stern, S. R. (2004). Expressions of Identity Online: Prominent Features and Gender Differences in Adolescents' World Wide Web Home Pages. Journal of Broadcasting \& Electronic Media, $48(2), 218-243$.

Thompson, E.C., \& Thianthai, C. (2008). Attitudes and Awareness toward ASEAN: Summary of Findings from a Ten Nation Survey (Summary Report). Jakarta: The ASEAN Foundation. 